\title{
Overview and Uncertainty Analysis for an Irrigation Flow Measurement Facility
}

\author{
Kyle Feist, P.E., M.ASCE ${ }^{1}$, \\ Zachary Markow, E.I.T ${ }^{2}$ and \\ Stuart Styles, P.E., D.Eng., M.ASCE ${ }^{3}$
}

${ }^{1}$ Senior Engineer, Irrigation Training and Research Center, California Polytechnic State University, 1 Grand Ave, Bldg. 8A, San Luis Obispo, CA 93407-0730; e-mail:

kfeist@,calpoly.edu

${ }^{2}$ Irrigation Engineer, Irrigation Training and Research Center, California Polytechnic State University, 1 Grand Ave, Bldg. 8A, San Luis Obispo, CA, 93407-0730; e-mail: zmarkow@,calpoly.edu

${ }^{3}$ Director, Irrigation Training and Research Center, California Polytechnic State University, 1 Grand Ave, Bldg. 8A, San Luis Obispo, CA, 93407-0730, e-mail: sstyles@calpoly.edu

\begin{abstract}
Accurate flow measurement is critical for modern water resource management. At the irrigation district level, instantaneous flow rates must be well-measured at key bifurcation points to reliably meet downstream demand in open channel systems while also minimizing diversions.

Furthermore, good flow measurement at each delivery point is a pre-requisite for successful volumetric water billing. Accuracy and repeatability are important characteristics of good flow measurement. Maximizing these traits requires periodic calibration to a common standard.

This paper presents an overview of calibration efforts and the engineering background behind an active flow measurement facility at the Irrigation Training and Research Center at California Polytechnic State University, San Luis Obispo (Cal Poly). The facility is fitted with two major flow measurement devices, a gravimetric weighing tank and a volumetric tank. Although both are used for comparison, verification, and calibration of closed pipe and open channel flow measurement devices, this report will focus on an uncertainty analysis for the gravimetric weighing tank.
\end{abstract}

\section{INTRODUCTION}

The Cal Poly Irrigation Training and Research Center (ITRC) operates several outdoor laboratories. The Water Resource Facility, shown in Figure 1, features a gravimentric weighing tank (weigh tank). 


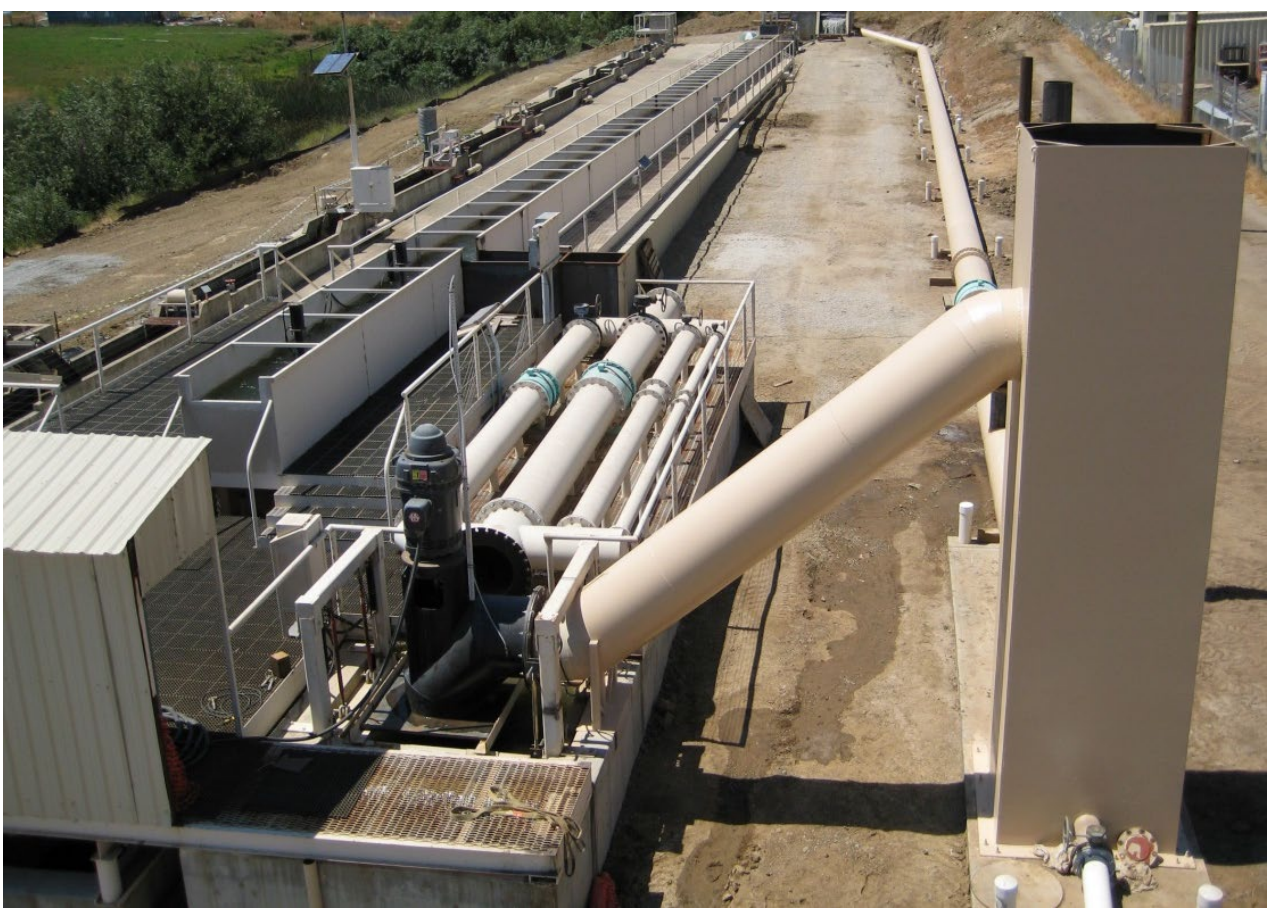

Figure 1. ITRC Water Resources Facility at Cal Poly, San Luis Obispo, CA.

The weigh tank was designed to accommodate comparisons with pipeline and open channel flow meters, as shown in Figure 2.

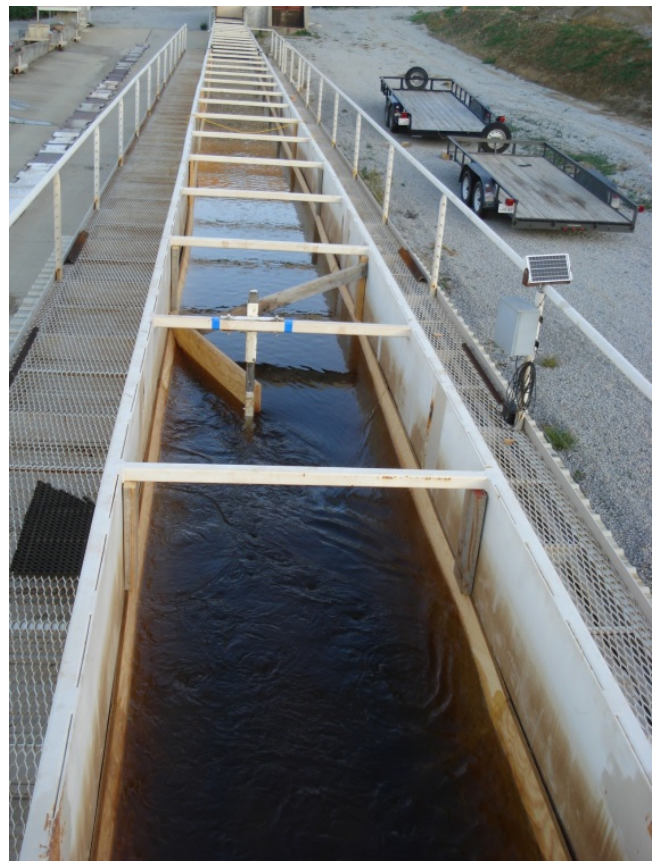

Figure 2. Acoustic Doppler velocity meters (ADVM) testing with obstructions in a 4-foot-wide open channel flume 


\section{METROLOGY BACKGROUND}

An international, uniform approach for computing and expressing measurement uncertainty was first provided by the International Standards Organization (ISO) Expression of Uncertainty and Measuremment, ISO/TAG 4/WG 3. For the United States, the ISO approach was accepted by the National Institue for Standards and Technology (NIST) in 1994, as described in NIST Technical Note 1297 (Taylor 2015).

NIST also operates a flow measurement calibration facility and provides documentation (NIST SP 250-73) describing the flow measurement system as well as policies and procedures for determining measurement uncertainty (Shinder and Marfenko 2006).

The design of the ITRC weight tank largely follows the NIST setup and this paper applies the same uncertainty analyses as presented in Shinder and Marfenko (2006).

\section{PHYSICAL CONFIGURATION}

The weigh tank is situated below the downstream end of a $300 \mathrm{ft}$ long flume with a four-foot square cross section. The flume can be supplied water from a wide variety of single speed and variable speed vertical turbine pumps. Several different demonstration and test flow meters are fitted in the pump discharge pipes. The water supply for the entire facility is a five-acre-foot reservoir.

Water can be directed to the top or bottom of the flume, as well as into and out of the weigh tank by manipulating pneumatic mud valves, as shown in Figure 3.

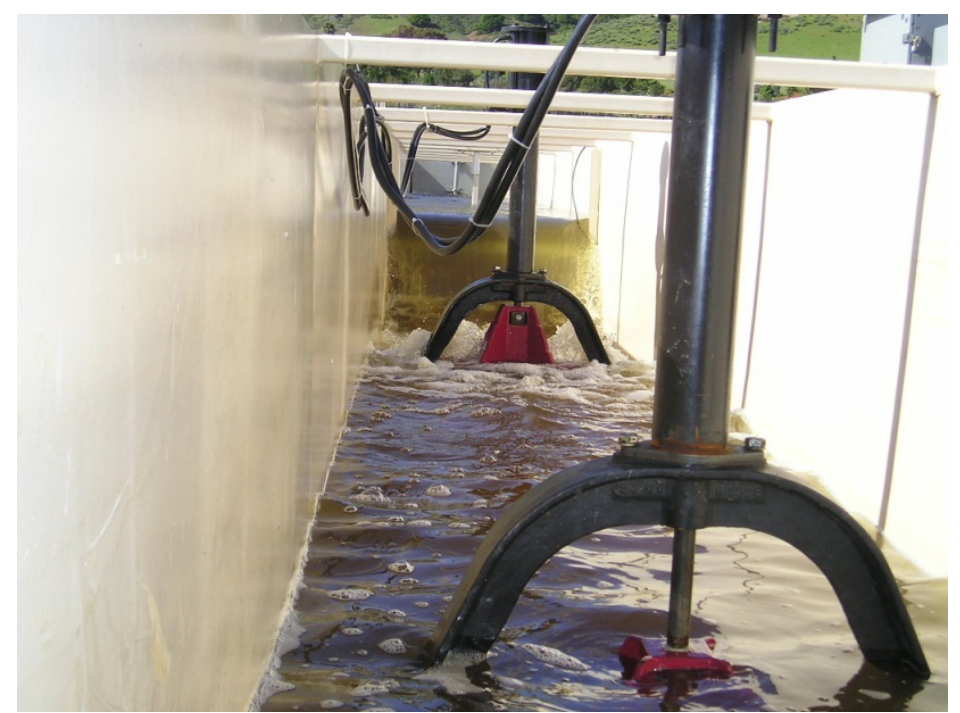

Figure 3. Pneumatic mud valves at the downstream end of the 300-foot open channel flume

\section{OPERATIONS AND COMPUTATIONS}

From an operator's perspective, a flow measurement is taken using the following procedure: 
1) Adjust the pumps and pnuematic mud valves so that a stable flow rate enters the diverter bay - where the water is directed by a pair of pnuematic mud valves controlling the flow to only one of two destinations:

a. Into a drain and back to the reservoir, or

b. Into the weigh tank

2) Measure the water temperature and enter the measured value into the computer program.

3) Verify or adjust the preset test START and STOP weights.

4) Close the weigh tank drain.

5) Open the weigh tank FILL mud valve.

6) Once the weight tank test STOP weight has been reached, actuate the diverter to bypass water from flowing into the weigh tank.

7) The volumetric flow rate is automatically computed within the programmable logic controller (PLC) and displayed on the laptop screen running a human-machine-interface (HMI) software. Record the number.

8) The tank drain is opened to empty the tank.

To take repetitive flow measurements, repeat steps 2 through 7 . All test parameters can be logged and saved to a .csv file for data backup and analysis.

Flow Measurement Computation. Each fill and empty cycle of the weigh tank produces a single, instantaneous flow measurement. The flow rate is calculated within the PLC (see Figure 4) as:

Where,

$$
Q=\frac{W}{\Delta t \times \rho}
$$

$$
\begin{aligned}
& \mathrm{Q}=\text { volumetric flow rate (cubic foot per second, CFS) } \\
& \mathrm{W}=\text { preset weight (lbs) } \\
& \Delta \mathrm{t}=\text { time ( } \mathrm{sec}) \\
& \rho=\text { water density (lbs/cubic foot) }
\end{aligned}
$$

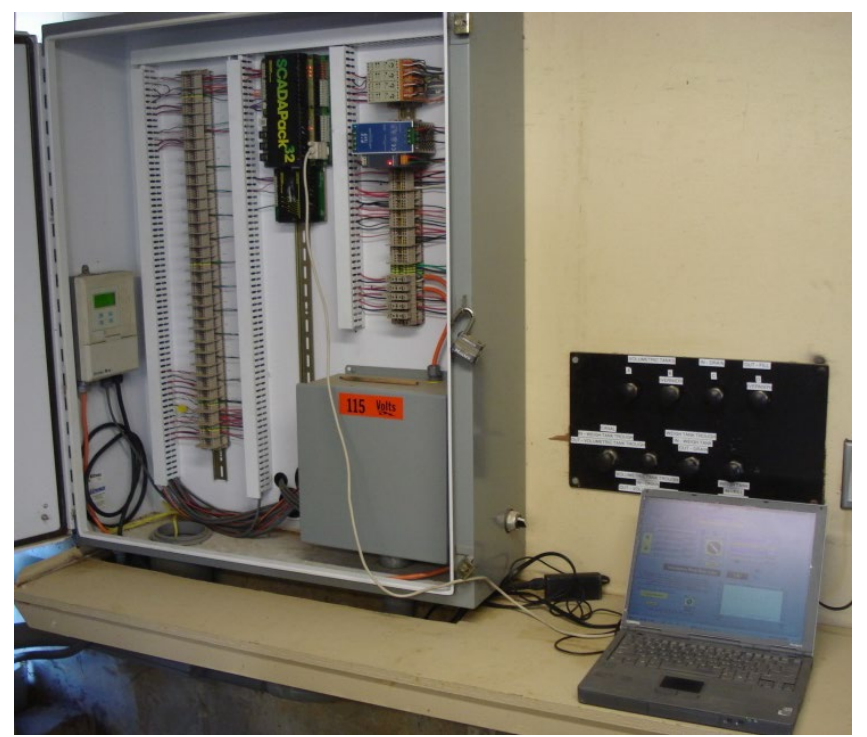

Figure 4. PLC and laptop running HMI software 
The tank and water weight are measured continuously by four load cells underneath the tank. The flow measurement concept is illustrated in Figure 5 and described below.

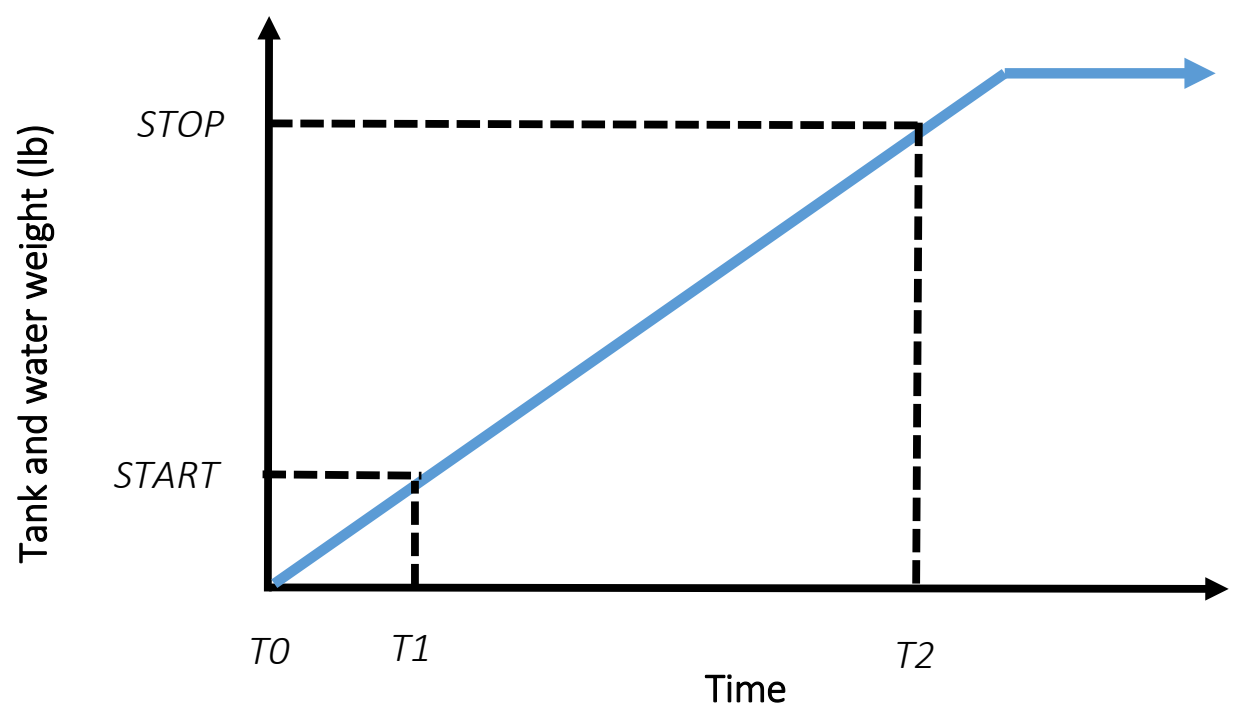

Figure 5. Tank and water weight over time throughout a flow measurement test

The weight, $W$, used in the computation is equal to the difference of two user entered set points a test START and STOP weight. The PLC timer is started the instant the tank weight surpasses the START set point (shown as T1) and stops accruing the instant the tank weight surpasses the STOP set point (at T2). Once the PLC timer stops, the flow measurement computation is automatically executed, with the input values and computed flow rate result displayed to the user (see Figure 4). The computations are reset upon emptying, the instant the tank weight drops below the START set point

The timing method described simplifies the process because the weigh tank inflow is constant before, during, and just after the flow measurement test. Therefore, complicated diverter geometries and controls intended to reduce diverter hysteresis (Shinder and Marfenko 2006) can be eliminated.

\section{UNCERTAINTY ANALYSIS}

The determination of flow measurement uncertainty described in this document follows the techniques used in Shinder and Marfenko (2006) and Taylor and Kuyatt (1994). Consider a process whose output $y$ is based on multiple inputs:

$$
y=f\left(x_{1}, x_{2}, x_{3} \ldots, x_{N}\right)
$$

As shown in Equation 1, the weigh tank flow measurement computation has three input components: weight, time and density. Since the uncertainty of each component ( $u_{\text {weight, }} u_{\text {time }}$ and $u$ density) are uncorrelated, the combined uncertainty $(u)$ is calculated as the square root of the sum of the component uncertainties squared (RSS): 


$$
u=\sqrt{u_{\text {weight }}^{2}+u_{\text {time }}^{2}+u_{\text {density }}^{2}}
$$

The result of the above equation is the combined uncertainty with a $68 \%$ confidence interval. A coverage factor of $k=2$ is used to compute the expanded uncertainty $\left(u_{\text {exp }}\right)$ with a $95 \%$ confidence interval:

$$
u_{\text {exp }}=k \times u
$$

Furthermore, each input component has multiple sub-components. For example, the weight component uncertainty can be determined by applying the same RSS method to each of the subcomponents including scale indication, calibration, storage effects, evaporation, and many other factors.

\section{MASS UNCERTAINTY}

Scale Indication. The weigh tank scale is equal to the sum of four load cell outputs. The analog load cell outputs are read by a Schneider Electric SCADAPack32 PLC with 15-bit precision. The smallest scale indication used by the PLC for internal computations can be computed as:

$$
\text { Scale Indication }(l b)=\frac{M W(l b)}{N \times 2^{x}}
$$

Where,

$M W=$ maximum load cell capacity of 15,000 pounds for each load cell, in pounds

$N=$ number of load cells

$x=$ minimum analog to digital converter bits for analog PLC inputs, unitless

Therefore, the scale indication can be computed as follows:

$$
\text { Scale Indication }(l b)=\frac{60,000 \mathrm{lb}}{4 \times 2^{15}}=0.458 \mathrm{lb}
$$

Because the scale indication is discrete, meaning that any value within a small range will be expressed as the same value ( 0.450 pounds will be measured as 0.458 pounds), the internal PLC scale indication follows a rectangular or uniform distribution. Because the load cell readings trigger the PLC timer start and stop, the highest impact of the scale indication uncertainty occurs at the start trigger event - where the scale indication uncertainty is applied to a smaller measured value (typically configured at 3,000 pounds).

Following Taylor (2015), the percent uncertainty component due to scale indication for a rectangular distribution when the load surpasses the start set point is equal to:

$$
u_{\text {scale indication } \%}=\frac{3,000.458 \mathrm{lb}-3,000 \mathrm{lbs}}{2 \times 3,000 \mathrm{lb} \times \sqrt{3}} \times 100=0.00441 \%
$$


Calibration. Periodic calibrations are conducted at the ITRC weigh tank. See the Scale Calibration section for more details.

The scale calibration uncertainty component is calculated using a least squares curve fitting routine (LINEST) in Excel with the most current calibration data. More specifically, a linear fit crossing the origin was used.

The 2017 calibration regression results comparing calibrated values with known, NIST-traceable weights are provided in Table 1.

Table 1. 2017 calibration regression results, with the linear fit crossing the origin

\begin{tabular}{|c|l|}
\hline Description & Value \\
\hline Slope & 1.000000 \\
\hline Standard error & 0.000107 \\
\hline $\mathrm{R}^{\wedge} 2$ & 0.999999 \\
\hline
\end{tabular}

Therefore, the latest calibration coefficient was found to be $1.0 \pm 0.000107$, resulting in a calibration component uncertainty of $0.0107 \%$.

Long-Term Drift. The uncertainty due to long-term drift is computed using historical linear regression (passing through the origin) results as the upper and lower bounds to a normal distribution, as listed in Table 2.

Table 2. Historical calibration regression results, with the linear fit crossing the origin.

\begin{tabular}{|c|c|}
\hline Year & $\begin{array}{c}\text { Standard Calibration Error } \\
\text { in Percent }\end{array}$ \\
\hline 2012 & .01946 \\
\hline 2015 & .05181 \\
\hline 2017 & .01072 \\
\hline
\end{tabular}

Taylor (2015) outlines the process to convert the upper and lower bounds to a standard deviation, assuming a normal distribution, as shown in Equation 2:

$$
\text { Component Uncertainty } \%=\frac{\text { abs (Upper bound }- \text { Lower bound) }}{2 \times 3} \quad \text { (Equation 2) }
$$

Inputs to the equation above are listed in Table 3, based on data provided in Table 2.

Table 3. Calibration regression data used to determine calibration component uncertainty.

\begin{tabular}{|c|c|}
\hline Description & Value \\
\hline Upper bound & 0.05181 \\
\hline Lower bound & 0.01072 \\
\hline
\end{tabular}

Applying the Table 3 values to the equation presented yields:

$$
u_{\text {long-term drift } \%}=\frac{a b s(0.05181-0.01072)}{2 \times 3}=0.0068 \%
$$


Buoyancy Correction. Archimedes' Law states that a mass fully or partially submerged in a fluid or gas will experience an upward force equal to the weight of the displaced fluid or gas. Moreover, during subsequent use, it is expected that the air and water temperatures will fluctuate away from the air and water temperatures that were present during the weigh tank calibration process. The buoyancy correction uncertainty component accounts for this fact.

The true mass can be calculated using the following (Schinder and Marfenko 2006):

$$
\text { True Weight }(l b)=\frac{\text { Measured Weight }(l b)}{\left(1-\frac{\text { Air Density }}{\text { Water Density }}\right)}
$$

The uncertainty for buoyancy correction is computed as the standard deviation of the maximum expected variations in water and air temperatures as listed below in Table 4.

Table 4. Factors used to compute buoyancy uncertainty

\begin{tabular}{|l|c|c|}
\hline \multicolumn{1}{|c|}{ Item } & \multicolumn{1}{|c|}{$\begin{array}{c}\text { Minimum } \\
\text { Correction }\end{array}$} & \multicolumn{1}{|c|}{$\begin{array}{c}\text { Maximum } \\
\text { Correction }\end{array}$} \\
\hline Apparent Weight $(\mathrm{lbs})$ & \multicolumn{2}{|c|}{27,000} \\
\hline Air temperature $(\mathrm{deg} \mathrm{F})$ & 40 & 90 \\
\hline Air density $\left(\mathrm{lbs} / \mathrm{ft}^{3}\right)$ & .0794 & .0722 \\
\hline Water temperature $(\mathrm{deg} \mathrm{F})$ & 50 & 80 \\
\hline Water density $\left(\mathrm{lbs} / \mathrm{ft}^{3}\right)$ & 62.411 & 62.218 \\
\hline True Weight $(\mathrm{lbs})$ & 27034 & 27031 \\
\hline Error $(\%)$ & .00127 & .00116 \\
\hline
\end{tabular}

Using Equation 2, the upper and lower bounds are converted to a standard deviation for normal distributions as shown in Table 5. The half width is defined as half of the difference between the upper bound and lower bound.

Table 5. Buoyancy uncertainty values computed using Equation 3

\begin{tabular}{|c|c|c|}
\hline Item & Lower Bound & Upper Bound \\
\hline Apparent weight (lbs) & \multicolumn{2}{|c|}{27,000} \\
\hline Change in apparent weight due to buoyancy effects (lbs) & 31 & 34 \\
\hline Difference (lbs) & \multicolumn{2}{|c|}{3.04} \\
\hline Half width (lbs) & \multicolumn{2}{|c|}{1.52} \\
\hline Absolute uncertainty (\%) & \multicolumn{2}{|c|}{0.51} \\
\hline Relative buoyancy uncertainty (\%) & \multicolumn{2}{|c|}{$.0019 \%$} \\
\hline
\end{tabular}

Therefore, the uncertainty due to buoyancy correction was found to be $0.0019 \%$.

Splashes and Leaks. After inspection, it was determined that splashes and leaks are negligible, as none were visible. As such the uncertainty due to leaks is assumed to be $0 \%$.

Storage Effects. Storage effects represent the unknown changes in water density during a test. All other storage volumes, such as within the diverter area, were not considered because of the specific timing protocol explained in the Operations and Computations section. 
A reasonable change in water temperature of 0.1 deg Kelvin could be probable due to the potential for mixing of the stratified water temperature layers within the reservoir.

The uncertainty due to storage effects was calculated using Equation 2, where the upper and lower density variation bounds are converted to a standard deviation for normal distributions as shown in Table 6.

Table 6. Factors used to compute storage effects uncertainty

\begin{tabular}{|l|c|}
\hline \multicolumn{1}{|c|}{ Item } & Value \\
\hline Mean water density $\left(\mathrm{lbs} / \mathrm{ft}^{3}\right) @ 60 \mathrm{deg} \mathrm{F}$ & 62.308 \\
\hline Reasonable change in water temperature $(\mathrm{deg} \mathrm{K})$ & 0.1 \\
\hline Change in water density $\left(\mathrm{lbs} / \mathrm{ft}^{3}\right)$ per deg K & 0.00032 \\
\hline Change in water density $\left(\mathrm{lbs} / \mathrm{ft}^{3}\right)$ for $0.1 \mathrm{deg} \mathrm{K}$ & 0.000032 \\
\hline Absolute uncertainty $\left(\mathrm{lbs} / \mathrm{ft}^{3}\right)$ & 0.0000054 \\
\hline Relative uncertainty (\%) & 0.000008 \\
\hline
\end{tabular}

Therefore, the uncertainty due storage effects is assumed to be negligible (zero).

Evaporation Uncertainty. Evaporation uncertainty was calculated using an equation from an adjusted ASHRAE equation (Labohm 1971):

Where,

$$
\text { Evaporation }\left(\frac{l b}{h r-f t^{2}}\right)=\frac{68.3+(32 \times V)}{Y} \times\left(P_{w}-P_{a}\right)
$$

$\mathrm{V}=$ wind velocity (mph)

$\mathrm{Y}=$ latent heat of water at water temperature (btu/lbs)

$\mathrm{P}_{\mathrm{w}}=$ saturation vapor pressure at the water temperature (in $\mathrm{Hg}$ )

$\mathrm{P}_{\mathrm{a}}=$ saturation vapor pressure at the air dew point (in $\mathrm{Hg}$ )

The mean expected evaporation was calculated using the assumptions listed in Table 7.

Table 7. Assumptions and factors used to compute evaporation uncertainty

\begin{tabular}{|l|c|}
\hline \multicolumn{1}{|c|}{ Item } & Value \\
\hline Wind velocity (mph) & 0 - surrounded by structures \\
\hline Water temperature (deg F) & 70 \\
\hline Air temperature (deg F) & 70 \\
\hline Relative humidity (\%) & 30 \\
\hline Latent head of water at water temperature (btu/lbs) & 1106 \\
\hline Sat. vapor pressure of water (in Hg) & 0.74 \\
\hline Air dew point (deg F) & 53 \\
\hline Sat. vapor pressure at air dew point (in Hg) & 0.41 \\
\hline Lowest test flow (GPM) & 100 \\
\hline Typical maximum test weight (lbs) & 27,000 \\
\hline Longest test time (hr) & 0.539 \\
\hline Tank surface area (ft $\left.{ }^{2}\right)$ & 81 \\
\hline
\end{tabular}

The maximum evaporation was calculated as $0.89 \mathrm{lbs}$ and the minimum evaporation is assumed to be half of the maximum, at $0.445 \mathrm{lb}$. 
Using Equation 2, the upper and lower bounds are converted to a standard deviation for normal distributions, as shown in Table 8.

Table 8. Factors used to compute evaporation uncertainty

\begin{tabular}{|l|c|c|}
\hline \multicolumn{1}{|c|}{ Item } & Lower Bound & Upper Bound \\
\hline Apparent Weight (lbs) & \multicolumn{2}{|c|}{27,000} \\
\hline Error due to evaporation effects (lb.) & 2.54 & 5.09 \\
\hline Absolute difference error (lbs) & \multicolumn{2}{|c|}{2.54} \\
\hline Half width (lb.) & \multicolumn{2}{|c|}{0.0016} \\
\hline Relative evaporation uncertainty (\%) & \multicolumn{2}{|c|}{0.0016} \\
\hline
\end{tabular}

Therefore, the uncertainty due evaporation uncertainty was found to be $0.0016 \%$

Timer Actuation Uncertainty. With a PLC scan frequency of $128 \mathrm{MHz}$, the uncertainty in timer actuation is assumed to negligible.

Timer Resolution Uncertainty. The timer duration value is saved to a 16-bit integer register with $2^{16}$ or 65,536 increments and a resolution of 0.1 seconds. A flow measurement test timer duration for the maximum flow rate of 8 CFS is about 60.75 seconds.

Using the values above, the timer resolution uncertainty can be calculated (assuming a uniform distribution) as:

$$
u_{\text {timer resolution }} \%=\frac{60.8 \text { seconds }-60.7 \text { seconds }}{2 \times 60.75 \text { seconds } \times \sqrt{3}} \times 100=0.0476 \%
$$

Timer Calibration Uncertainty. The internal SCADAPack32 PLC timer is specified at a published \pm 1 minute per month. This equates to a timer calibration uncertainty of $0.0023 \%$.

Density Estimation Uncertainty. Using a NIST-traceable, digital thermometer (such as McMaster-Carr part number 3569K58), water temperature measurements can be made with a $\pm 0.5 \mathrm{deg} F$ uncertainty. This equates to a density uncertainty of $\pm 0.005 \mathrm{lbs}$ per cubic foot or a relative uncertainty of $0.008 \%$, assuming a mean water temperature of $62.3 \mathrm{deg} \mathrm{F}$.

\section{EXPANDED UNCERTAINTY BUDGET}

The various component uncertainties are combined using the RSS computation described in this paper. The results are listed in Table 9. 
Table 9. Standard and expanded uncertainty for the ITRC weigh tank

\begin{tabular}{|c|c|}
\hline Component & Uncertainty (\%) \\
\hline Mass Uncertainty & 0.0044 \\
\hline Scale indication, $U_{\text {scale }}$ & 0.0107 \\
\hline Scale calibration, $U_{\text {calib }}$ & 0.0068 \\
\hline Long-term scale drift, $U_{\text {drift }}$ & 0.0019 \\
\hline Buoyancy correction, $U_{\text {buoy }}$ & 0.0000 \\
\hline Leaks, $U_{\text {leaks }}$ & 0.0000 \\
\hline Storage effects, $U_{\text {storage }}$ & 0.0016 \\
\hline Evaporation, $U_{\text {evap }}$ & $\mathbf{0 . 0 1 3 7}$ \\
\hline Total Mass Uncertainty & 0.0000 \\
\hline Collection Time Uncertainty & 0.0476 \\
\hline Timer Actuation, $U_{\text {onoff }}$ & 0.0023 \\
\hline Timer resolution, $U_{\text {tres }}$ & $\mathbf{0 . 0 4 8}$ \\
\hline Timer calibration, $U_{\text {time }}$ & \\
\hline Total Time Uncertainty & 0.0080 \\
\hline Water Density Uncertainty & $\mathbf{0 . 0 0 8 0}$ \\
\hline Density estimation, $U_{\text {dens }}$ & $\mathbf{0 . 0 5 0 0}$ \\
\hline Total Density Uncertainty & \\
\hline Combined Uncertainty & $\mathbf{0 . 1 0 0}$ \\
\hline Coverage factor $(k=2)$ & \\
\hline $\begin{array}{l}\text { Expanded Uncertainty } \\
\text { (95\% confidence level) }\end{array}$ & \\
\hline
\end{tabular}

Based on the results of the expanded uncertainty analysis, the ITRC weigh tank can provide a flow measurement standard with $\pm 0.1 \%$ uncertainty with a $95 \%$ confidence interval for future flow measurements.

\section{SCALE CALIBRATION PROCEDURES}

Although the weigh tank is not a commercial scale and thus not regulated by local weights and measures authorities, the ITRC calibration process for the weigh tank load cells follows similar NIST guidelines prescribed by the NIST Handbook 44 in terms of:

- Testing protocol: Substitution test (N.1.11 - Section 2)

- Minimum test weights: 1000 lbs (Table 4 - Section 2)

ITRC contracts with a local scale company to provide up to sixteen 1,000-pound NIST traceable weights. NIST-traceable weight certificates are available upon request.

The calibration sequence followed by ITRC is also outlined in Shinder and Marfenko (2006), as described below; at each step the known load and the measured load are recorded:

1. The scale is zeroed.

2. A test load (typically 8,000 lbs) is applied.

3. The test load is removed.

4. Water is added until the scale displays the test load weight.

5. The test load is applied (with water in the tank).

6. The test load is removed (with water in the tank).

7. Water is added until the scale displays the current weight plus the test load weight. 
The process is repeated until the maximum scale load is reached, and then the process is reversed to verify repeatability.

\section{DISCUSSION}

Developing and maintaining a NIST-traceable flow measurement standard requires substantial efforts and funding. The authors would like to acknowledge the financial support provided by the United States Bureau of Reclamation, Mid-Pacific Region (USBR-MPR) that have made possible the maintenance and traceability analysis provided herein.

The ability to compare various pipeline and open channel flow measurement devices to a standard with low ( $\pm 0.1 \%$ at $95 \%$ confidence interval) uncertainty has been critical in calibrating and validating those flow measurement devices for use in the field. ITRC plans to continue maintaining NIST-traceability for the weigh tank into the foreseeable future and using the weigh tank as a standard for future laboratory experimentation.

Example use cases for recent flow measurement device validation include: submerged ADVMs, non-contact ultrasonic and laser velocity meters, pipeline magnetic meters with and without good grounding practices and various hydraulic straightening vanes typically upstream of pipeline flow meters in instances of poor hydraulic conditions. In most cases, the results of these laboratory tests will be published in the near future.

In addition to the weigh tank, ITRC (with funding and support from USBR-MPR) has constructed a volumetric tank for the calibration and validation of flow measurement devices at flow rates that exceed the 8 cubic feet per second capacity of the weigh tank. NIST-traceable analyses for the volumetric tank are ongoing and may be the focus of a future paper.

\section{REFERENCES}

Labohm, G. (1971) Heating and Air Conditioninig of Swimming Pools. Gesundheits-Ingenieur. P. 72-80. March 1971 (Germany).

NIST. (2015). Specifications, Tolerances, and other Technical Requirements for Weighing and Measuring Devices. Adopted by the $99^{\text {th }}$ National Conference on Weights and Measures 2015. Available at: http://www.nist.gov/pml/wmd/pubs/hb44.cfm

Shinder, I.I. and Marfenko, I.V (2006). NIST Calibration Services for Water Flowmeters Water Flow Calibration Facility. NIST Special Publication 250-73. Available at: https://www.nist.gov/publications/nist-calibration-services-water-flowmeters-water-flowcalibration-facility

Taylor, B.N and Kuyatt, C.E. (1994). Guidelines for Evaluating and Expressing the Uncertianties of NIST Measuremet Results. NIST Technical Note 1297. Available at: http://physics.nist.gov/Pubs/guidelines/TN1297/tn1297s.pdf

Taylor, B.N. (2015). The NIST Reference on Constants, Units and Uncertainty. Web Encyclopedia. A NIST Physical Measurmeent Laboratory Service. Last updated: 2015. Accessed 2015. Available at: http://physics.nist.gov/cuu/index.html 